\title{
Digital Innovation and Business Process Management: Opportunities and Challenges as Perceived by Practitioners
}

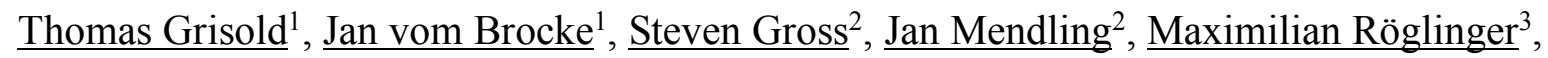 \\ $\underline{\text { Katharina Stelzl }}^{3}$
}

${ }^{1}$ University of Liechtenstein, Liechtenstein

(thomas.grisold@uni.li; jan.vom.brocke@uni.li)

${ }^{2}$ Vienna University of Economics and Business, Austria

(jan.mendling@wu.ac.at; steven.gross@wu.ac.at)

${ }^{3}$ University of Bayreuth, Germany

(maximilian.roeglinger@fim-rc.de; katharina.stelzl@fim-rc.de)

\begin{abstract}
This report summarizes a large-scale online workshop series focusing on the connection between digital innovation and business process management (BPM). The motivation behind our format was to complement the primarily conceptual claims in this field of research with in-depth insights from organizational practice. The format covered four consecutive onehour workshops, each involving an average number of 120 practitioners and several academics. Each workshop shed light on specific aspects that appear important in the context of digital innovation and BPM. We collected data by means of discussions during the sessions, as well as from two surveys completed respectively before and after the workshop. Based on our findings, we identify three research directions to advance research on the intersection of digital innovation and BPM. We suggest (1) exploring the role of BPM in digital innovation, (2) scoping digital innovation activities within BPM projects, and (3) aligning organizational structures to support BPM-driven digital innovation activities. We point to several concrete avenues for future empirical research in this field.
\end{abstract}

Keywords. Business process management, digital innovation, digital technologies, explorative BPM, process redesign

\footnotetext{
*Please cite as:

Grisold, T., vom Brocke, J., Groß, S., Mendling, J., Röglinger, M., Stelzl, K. (forthc.). Digital Innovation and Business Process Management: Opportunities and Challenges as Perceived by Practitioners. Communications of the Association for Information Systems.
}

This article has been accepted for publication in the Communications of the Association for Information Systems but has not been through the copyediting, typesetting, pagination and proofreading process. This may lead to differences between this version and the final version. 


\section{Introduction}

Business Process Management (BPM) is concerned with the analysis, design, and improvement of business process work (Dumas, La Rosa, Mendling, \& Reijers, 2018). Over the past decades, the BPM field has developed frameworks, methods, and tools for supporting process-related management activities in practice. The ends of these approaches are to design and improve business processes and working routines as well as increasing efficiency, effectiveness, and customer experience (Kreuzer, Röglinger, \& Rupprecht, 2020). Recent studies find that the majority of BPM methods do not support innovation and thus fail to capitalize on the opportunities associated with digital innovation (Groß, Malinova, \& Mendling, 2019; Kerpedzhiev, König, Röglinger, \& Rosemann, 2020; Mendling, Pentland, \& Recker, 2020; Van Looy, 2021; vom Brocke, Denner, et al., 2021). This observation has been affirmed by recent calls for redeveloping BPM to become more explorative and opportunity-driven (Grisold, Gross, Röglinger, Stelzl, \& vom Brocke, 2019; Helbin \& Van Looy, 2021; Rosemann, 2014).

The integration of BPM and digital innovation comes with challenges. Mendling et al. (2020) argue that the core assumptions of BPM cannot account for the emerging and unfolding opportunities associated with digital innovation. This is important given that digital technologies provide unprecedented opportunities for new business models, products, and services (Berger, Denner, \& Roeglinger, 2018; Yoo, Henfridsson, \& Lyytinen, 2010). The question of how organizations do or can embrace digital innovation within their business process work remains largely unexplored (Groß et al., in press; Mikalef \& Krogstie, 2020). What are the perceived opportunities and challenges associated with digital innovation in BPM? Answering this question is essential for the development of new frameworks, methods, and tools in order to inform management activities (Baiyere, Salmela, \& Tapanainen, 2020; Mendling et al., 2020).

We report on new insights into the interplay between BPM and digital innovation which we gained through a large-scale online workshop series with 150 registered process practitioners. The series consisted of four consecutive sessions which each lasted one hour. Each session entailed (1) a short presentation held by an academic, and (2) a discussion with practitioners about their related experiences and needs. The four sessions addressed the following themes:

- Strategic alignment of BPM activities with digital innovation activities

- Similarities and differences between BPM and digital innovation

- Types and features of digital technologies for process innovation

- Coordination and integration of digital innovation within BPM initiatives

In this report, we draw on three data sources: (1) around 25 questions and discussions between academics and practitioners during the online sessions, (2) a survey sent out prior to the first online session ( 80 respondents), and (3) a survey sent out after the last session ( 27 respondents). Following the observation that insights from practice are an important source for advancing BPM research (Grisold, Mendling, Otto, \& vom Brocke, 2020), our report points to three avenues for future research. First, it is important to explore the role that BPM plays in digital innovation. Second, we require empirical evidence on how digital innovation can be fostered within BPM projects. Third, we need to develop a theoretical perspective on the role of organizational structures that best enable digital innovation and BPM. 


\section{General information about the workshop series}

\subsection{Description and outline}

To date, there has been a lack of empirical evidence on the interplay between concepts from BPM and digital innovation have been largely missing. In order to address this lack of insights, the University Liechtenstein, the Vienna University of Economics and Business, and the University of Bayreuth launched a large-scale online workshop series in November 2020 that was presented to practitioners as an "Innovation Breakfast". The key idea behind this format was to present recent research on the intersection between BPM and digital innovation. As academics, we wanted to learn about practitioners' needs, perceived opportunities, and challenges. The format consisted of four online sessions which were held in the mornings and each lasted one hour (8.30-9:30 am). The workshops were held in German and via Zoom.

Each session included two parts. The first part covered a presentation by one or more academics. This lasted 25-30 minutes. The academic presentations were held by the authors of this report, whose current research focuses on digital innovation in the context of BPM. In the second part of each session, there was an open discussion round in which practitioners raised questions by making comments in the Zoom chat or using the speak function. This part lasted around 25-30 minutes. In all sessions, one co-author of this paper (Thomas Grisold) acted as the host. In each session, he welcomed all participants, introduced the theme and the speaker, and moderated the discussion between practitioners and academics.

\subsection{Participants}

We reached out to BPM practitioners who are interested in or dealing with digital innovation in their daily business process work. We advertised the event via LinkedIn, Twitter, newspaper reports (published in Liechtenstein and Germany) as well as in our personal industry networks. In total, we counted 150 registered attendants from Liechtenstein, Austria, Switzerland and Germany. On average, each session was attended by 120 practitioners. We sent out a survey prior to the first session to obtain information about participants. Overall, 80 participants responded to the survey. This revealed information about [A] the participants background, [B] the size of organizations, and [C] the five most interesting themes from the participants' perspective. Figure 1 shows the results. 


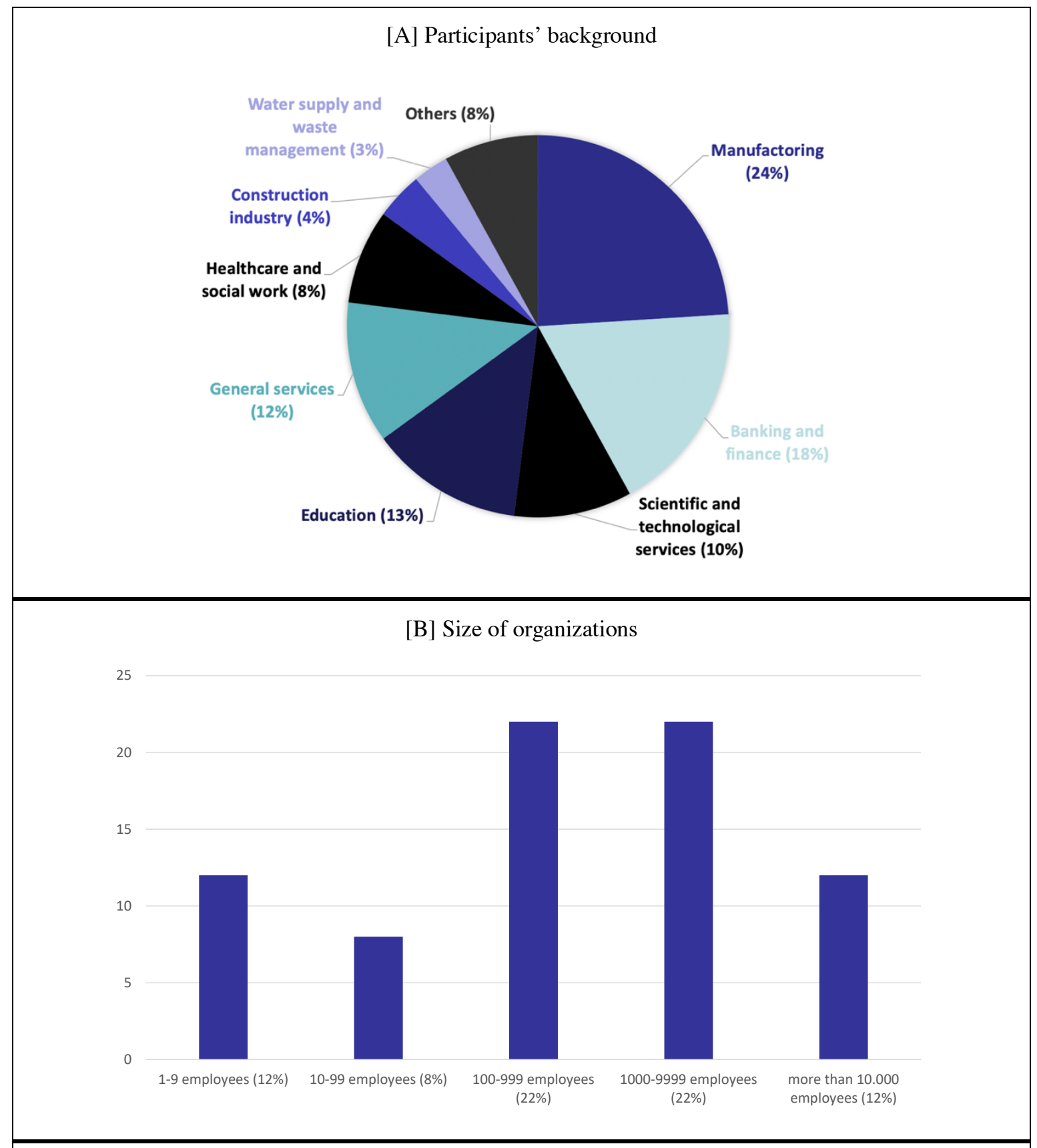

[C] Five most interesting themes for participants

1. How to design and manage processes to account for ever-changing business demands?

2. How to develop a digital mindset and select the most relevant digital technologies?

3. How to align processes, skills, and culture?

4. How to create awareness around digital innovation?

5. How to prioritize change and innovation in business process work?

Figure 1: Information about participants' background, organizations, and major interests with respect to the workshop content 


\section{Summaries of the four sessions}

In the following, we provide an overview of the four sessions. We outline the content of the academic presentation as well as the following discussion with practitioners.

\subsection{Session 1: “Corporate strategy and process innovation", Jan vom Brocke}

\section{Academic Presentation}

The first session addressed the topic "Corporate strategy and process innovation". It was held by Jan vom Brocke from the University of Liechtenstein. The presentation conveyed three central messages.

First, vom Brocke argued that business processes should be at the center of innovation processes. This is because processes are the means through which new products or services are created or delivered. Drawing on the example of Nespresso, he suggested that innovation does not necessarily result in new final products or services (e.g., customers still drink coffee) but changes the way products or services are delivered (i.e., using capsules in special machines). Hence, processes as key artifacts should be integrated into innovation activities from early on. The second point built on the fact that innovation is often enabled through new technologies. According to vom Brocke, one should consider the role that technologies should play in processes. More specifically, he introduced the concept of task-technology fit and explained that, in order to use new technologies in process work, it is important to ensure there is an alignment between the technology, the people who should use the technology, and the task to be carried out with the technology.

Finally, vom Brocke argued that changes in processes need to align with other organizational activities and capabilities. Introducing the BPM billboard (vom Brocke, Mendling, \& Rosemann, 2021), he explained that process innovation initiatives should account for the broader situation of the organization. This includes the overall strategy, the context in which the organization is operating, several capabilities (including methods used, culture, governance, people, and alignment), the implementation of isolated projects, as well as the evaluation of results. Vom Brocke stressed the role of processes within innovation initiatives. He emphasized that processes should be considered within the broader (organizational) context in which they are embedded.

\section{Discussion with Practitioners}

The succeeding discussion revolved around four themes.

- Practitioners expressed concerns in relation to the mindset needed for digital innovation initiatives in the context of business processes. One participant suggested that processes are often associated with providing technocratic value; they are considered necessary means to deliver products and services. Consequently, there is little dedication towards process improvement. Another participant agreed and suggested that use cases and success stories can help create awareness; however, he explained that he lacks guidance with respect to how such cases look. In a similar vein, another participant stressed that the management in his organization is primarily concerned with marketing and R\&D activities when they start innovation projects. There is little commitment to thinking through innovation potentials by means of business processes. 
- One participant discussed the role of timing in relation to process innovation; when should innovation initiatives start or end? In line with vom Brocke's presentation, he affirmed that continuous innovation seems desirable, but it is not clear how this can be achieved within everyday process work.

- It was pointed out that an organization still needs to adhere to rules and standards - for example, to ISO norms. In practice, it seems hard to think "out of the box" in light of these regulations, and it would be desirable if there were more specific frameworks or methods which take such constraints into account.

- Two participants asked if or to what extent one can measure process innovation outcomes. One suggestion was to develop process innovation KPIs which are directly related to the progress of innovation activities.

\subsection{Session 2: "Digital Innovation through process management", Jan Mendling}

\section{Academic Presentation}

The second session centered around the types of digital innovation that can be harnessed through BPM. It was held by Jan Mendling from the Vienna University of Economics and Business. Mendling (with reference to Mendling et al., 2020) emphasized that BPM and digital innovation are based on different underlying assumptions.

First, he described that traditional BPM has often separated problem and solution space. This means that the problem space is first investigated (e.g. through process analysis) before a new solution is proposed. By contrast, digital innovation unfolds as a co-evolution of problem and solution space, as well as a reciprocal influence between these two.

Furthermore, traditional BPM has often followed a top-down design approach, in which a process is created and then implemented. This is in contrast, which unfolds in a bottom-up fashion. To account for the potentials of digital innovation, BPM methods and tools need to embrace flexibility and adoption. One example is Adaptive Case Management (ACM), which describes process boundaries rather than pre-defined sequences of actions.

Mendling also pointed out that traditional BPM has often built on one-off initiatives. On the contrary, digital innovation unfolds continuously. Thus, BPM approaches should be concerned with the continuous identification of potential opportunities. Mendling stressed that process mining can be an enabler in this regard, as it enables continuous monitoring of process data.

Furthermore, Mendling argued that classical BPM approaches have often located innovation activities within business process work. However, digital innovations are unbound. An example of digital innovation is the encapsulating of functionality into reusable units, e.g. in the form of components-based development in software engineering. However, BPM has rarely made use of these unbound innovation opportunities.

The presentation concluded that BPM and digital innovation are converging. This is particularly represented in recent attempts to make BPM more ambidextrous - in other words, exploiting improvement opportunities within business process work but also embracing innovation opportunities outside of process work. 


\section{Discussion with Practitioners}

Following the academic presentation, there was a discussion with the practitioners centering around four different topics, namely context, risk, knowledge, and customer centricity.

- Practitioners raised the question of whether a given context influences an organization's orientation towards BPM and digital innovation. In line with vom Brocke's presentation, it was referred to the BPM Billboard (vom Brocke, Mendling, et al., 2021), which is used to determine the context of an organization and to align BPM initiatives with strategic objectives.

- Another point concerned the risk associated with the integration of digital technologies and how organizations can assess these risks. According to practitioners, it is important to find ways to cautiously approach these aspects, but they lack tools and frameworks for doing so. Mendling proposed testing hypotheses continuously. This form of experimentation within organizations should happen in shorter intervals to minimize the impact of negative outcomes.

- Practitioners raised the question of where process knowledge should be located within organizations. Implications of the presented content are that organizations may need to redesign established structures.

- One practitioner suggested that a clear orientation towards customer needs would automatically lead to innovations. He argued that the market may exert the pressure to engage with certain types of innovation, and wondered if it would not be safer to listen to the market before innovating, and not the other way around. Another participant responded that customers are often not aware of their actual needs as long as a supply does not exist.

\subsection{Session 3: "Digital technologies for process innovation", Maximilian Röglinger}

\section{Academic Presentation}

The third session addressed the role of digital technologies for process innovation. Therefore, Maximilian Röglinger presented various classifications of digital technologies, ideas on how potential applications of digital technologies in business processes can be identified, and 'Digital Process Innovation Heuristics' to foster digital process innovation.

First, Röglinger differentiated digital technologies from other technology types (e.g., nano, neuro, green, and bio technologies). Accordingly, digital technologies are characterized by reprogramability, homogenization of data, and a self-referential nature (Yoo et al., 2010). To structure the high number of digital technologies, he presented two high-level classifications commonly used in industry: the SMAC acronym (social, mobile, analytics, and cloud technologies) (Dewan and Jena 2014; Evans 2016) and the DARQ acronym (distributed ledger, artificial intelligence, extended reality, and quantum computing) (Accenture 2019) as well as the Gartner Hypecycle for Emerging Technologies (Gartner, 2019).

To increase understanding of digital technologies, Röglinger presented nine purpose-oriented archetypes of digital technologies: Connectivity \& Computation, Platform Provision, Mobility, Sensor-based Data Collection, Actor-based Data Collection, Analytical Insight Generation, Self-dependent Material Agency, Augmented Interaction, and Natural Interaction (Berger et al., 2018). Second, to identify potential applications of digital technologies in business processes, Röglinger proposed the technology-process matrix as a tool in line with task-technology 
fit theory (Denner, Püschel, \& Röglinger, 2018). On the one dimension of the matrix, the presented archetypes can be used to structure the field of action. On the other dimension, the investigated business process should be defined on the level of sub-processes. Finally, a match between each archetype and each sub-process can be investigated in order to derive ideas and projects for potential applications of digital technologies in business processes. Third, Röglinger underpinned the need for digital process innovation, i.e., the use of digital technologies to create process innovation. In order to structure the idea generation process, digital process innovation heuristics (including various examples) were presented which were derived from the innovation activities of digital start-ups.

\section{Discussion with Practitioners}

The subsequent discussion focused on the use of digital technologies in business processes in general as well as the specific use of artificial intelligence (AI) in business processes.

- One practitioner suggested using AI for data processing, especially to complement missing data. Another practitioner saw high potential in using AI for data analyses, especially performance prediction of business processes. Finally, Röglinger suggested using AI as an enabler for creativity in fostering automated process innovation, e.g., by using constructive machine learning approaches.

- One practitioner asked about relevant evaluation criteria to assess the applicability of digital technologies for specific business processes under investigation. Therefore, the group discussed the relevance of maturity models that help structure relevant fields of action.

- One practitioner asked about the difference between process and business model innovation. This question was discussed from two perspectives: "Business model first, business process second" and "business process first, business model second". Hence, on the one hand, business processes help realize new business models, while new business models can build on (new) business processes.

\subsection{Session 4: "Re-Design of Processes", Katharina Stelzl and Steven Gross}

\section{Academic Presentation}

The last session focused on the integration of all innovation aspects mentioned in the previous three sessions. The presentation was held by Katharina Stelzl from the University of Bayreuth and Steven Gross from the Vienna University of Economics and Business. The presentation covered two parts.

In the first part, Steven Gross outlined the current research focus of the BPM community. Drawing on a recent literature review (Groß et al., 2019), he explained that most of the process redesign methods are concerned with increasing efficiency and effectiveness. Following recent streams in the literature, he explained that process innovation methods are beginning to pursue the development of new customer value through processes, products, and services. This constitutes a more radical approach to innovation. In line with the previous sessions, Gross stressed that exploration activities are particularly important in light of the potentials arising through digital technologies (e.g., with respect to the development of new products, services, and business models). 
In the second part, Katharina Stelzl presented a method for explorative process innovation activities. The "Five Diamond Method" (vom Brocke et al., 2020) was developed within a collaboration between the University of Liechtenstein, the Vienna University of Economics and Business, and the University of Bayreuth. Key to this method is to account for and integrate two dominant innovation factors, namely "market pull" and "technology push" factors. The method focuses on four central elements; the purpose of the organization, emerging technology opportunities, emerging business opportunities, and the integration of selected opportunities into new business process designs. Stelzl stressed that the method grants flexibility and freedom for the context in which it is applied (e.g. different types of industries).

\section{Discussion with Practitioners}

The discussion circled around two themes.

- Practitioners raised questions about the method and the relevance of the respective elements. Stelzl and Gross stressed that it is important to view the whole innovation initiative in terms of divergent and convergent thinking, where organizations continuously scan the environment for emerging opportunities and experiment with ways to integrate these opportunities into process designs. One practitioner pointed out that this seems challenging, as organizations are typically concerned with one-off innovation initiatives.

- Second, two practitioners expressed the need to learn more about specific techniques that can be deployed across the four elements of the Five-Diamond-Method. In other words, they indicated a need for techniques that are more specific with respect to the exploration of an organization's purpose, technology opportunities, business opportunities, and ways to design new processes. Stelzl explained that such methods would not usually fall into the realm of BPM research, although she pointed to an emerging discourse which is concerned with such questions (vom Brocke, Denner, et al., 2021).

\subsection{Additional insights from surveys}

In addition to the discussions that followed the academic presentations, we gained insights into the perceptions of practitioners through two surveys; one sent out prior to the first session (presurvey) and the other sent out after the last session (post-survey).

\section{Additional insights from the pre-survey}

Overall, 80 participants responded to the pre-survey. Besides general information about the participants (i.e., background, size of organization, and motivations to participate, as outlined in section 2.2.), we gained insights into the types of technologies that are perceived as important with respect to digital innovation. The survey showed that participants are primarily concerned with Artificial Intelligence (25\%), Robotic Process Automation (12\%), Process Mining (10\%), Internet of Things (8\%), Cloud Technology (7\%), Big Data (6\%), and Blockchain (6\%).

\section{Additional insights from the post-survey}

We sent out a survey after the last session to evaluate the online workshop series and to learn about the key take-aways by practitioners. The survey was completed by 27 participants. We asked two open-ended questions to better understand the needs of practitioners in relation to 
the innovation of business processes. The first question focused on themes and inputs which they found particularly useful for their work. The second question focused on aspects that could be explored in more detail. We were able to gain the following overall insights:

First, practitioners appreciated all sessions and the respective insights that were conveyed. All themes covered in the workshop series attracted equal interest. The respondents also stressed that they appreciated the presentation of specific methods and tools in each sessions. Second, the responses show that practitioners are in need of more specific tools and methods to realize innovation activities in their organizations. While they seemed to be able to relate to the methods, tools, and concepts discussed in the BPM literature, they also indicated they would need more specific guidelines to apply those concepts in their work. According to the respondents, this could also include examples and best practices from actual projects that were conducted. Overall, the respondents indicated that the format considered their needs and they could gain new insights about process innovation (average of 4.1 on a 5-point Likert scale).

\section{Directions for Future Research}

In this report, we set out to present how BPM practitioners perceive opportunities and challenges in relation to digital innovation and BPM. Summarizing the insights we gained from three data sources (i.e., practitioners' questions and notes after the academic presentations, presurvey, post-survey), we suggest three directions for future BPM research.

\subsection{Exploring the role of BPM in digital innovation}

The first implication pertains to the fact that there is little awareness that BPM can play an enabling role in digital innovation initiatives (Mendling et al., 2020). Practitioners acknowledge that digital technologies, such as AI or process mining, can substantially impact business process work. The perceived benefits of such technologies, however, are associated with increased efficiency and effectiveness. As one practitioner mentioned, innovation activities are commonly initiated in other departments, such as R\&D or marketing. BPM is concerned instead with the operationalization of new service or product ideas. The observation that BPM plays a peripheral role in innovation activities aligns well with the academic discourse. Here, it has been argued that BPM is even detrimental to innovation (Benner \& Tushman, 2003), and that innovation is an accidental by-product of traditional BPM (Berente \& Lee, 2014). Recent studies have been advancing the discourse on explorative BPM, by attempting to systematically integrate emerging innovation opportunities into business process work (Grisold et al., 2019; Groß et al., in press; Kohlborn, Mueller, Poeppelbuss, \& Roeglinger, 2014; Rosemann, 2014). Overall, however, we see that the BPM discourse is still largely concerned with exploitative BPM (i.e., attempts to increase the effectiveness and efficiency of existing business processes) (Groß et al., 2019; Kerpedzhiev et al., 2020; vom Brocke, Denner, et al., 2021).

Based on our findings we encourage future research to make contributions to understanding and demonstrating how BPM can play an enabling role in digital innovation. (Research direction 1). 
One way to promote awareness for the role of BPM in digital innovation is to collect and summarize real-world examples where processes are key to digital innovation (vom Brocke \& Mendling, 2018). The BPM literature offers some examples, such as Uber (Mendling et al., 2020), Rolls Royce's efforts to use 3-D printing for power systems (Wurm, Goel, Bandara, \& Rosemann, 2019), or Walmart's attempts to change offerings based on weather conditions (vom Brocke \& Grisold, 2020). Future research should further analyze the role of processes within various digital innovation projects.

\subsection{Scoping digital innovation activities within BPM initiatives}

We found that practitioners are unaware of how they should integrate digital innovation activities within their BPM projects. This is for different reasons. First, practitioners articulated the concern that they need to comply with standardization requirements and ISO norms. This impedes innovation. The second issue relates to timing. One discussion centered around the question of when such digital innovation projects should be set off, or whether there is a best time to start. Another perceived challenge refers to the evaluation of such initiatives; if innovation initiatives entail processes that are yet to be established, it is hard to evaluate their success. Several responses in the post-surveys stressed that practitioners appreciate real-world examples and detailed insights into how digital innovation activities have been realized in companies.

Based on our insights, we encourage future research to make contributions to further understanding and demonstrating how digital innovation can support BPM activities (Research direction 2).

From an academic point of view, we see that these aspects have been largely unexplored. Works that address the role of digital innovation in organizations are mainly conceptual. While they provide useful advice, such as accounting for emerging potentials of digital technologies (Mendling et al., 2020) or providing actors with more decision rights (Baiyere et al., 2020), there is little concrete guidance on how to manage BPM projects in the context of digital innovation. Recent frameworks, such as the BPM Billboard (vom Brocke, Mendling, et al., 2021), suggest planning BPM initiatives in terms of smaller projects (Lehnert, Linhart, \& Röglinger, 2016). Such claims can be relevant in the context of digital innovation. What is missing, however, are means to systematically select and assess the potentials of digital technologies, and evaluate the success of single projects.

We see several implications for BPM research. First and foremost, it is useful to translate conceptual statements about the role of BPM in digital innovations (Beverungen et al., 2020; Mendling et al., 2020) into tangible management advice. This entails contextual insights into how, when, and why (process) managers take decisions and how these decisions turn out (vom Brocke, Denner, et al., 2021). This appears important in light of ISO norms which force managers to balance between narrow process specifications on the one hand and unprecedented potentials of digital technologies on the other. We advocate for more descriptive and explanatory research designs to explore the relation of BPM in the context of digital innovations. This will lead to detailed knowledge about managerial actions and resulting dynamics. In-depth explanatory knowledge, in turn, leads to better prescriptive knowledge (Seidel \& Watson, 2020) 
to inform the design of appropriate BPM frameworks, methods, and tools (Grisold et al., 2020; Mendling et al., 2020; Simmert, Ebel, Peters, Bittner, \& Leimeister, 2019).

\subsection{Aligning organizational structures to realize digital innovations through BPM}

Practitioners expressed the need to better understand the role of organizational structures and capabilities to align BPM and digital innovation. The discussions as well as survey responses circled around the question of how managers can enable such activities. Two points stood out. First, practitioners need guidance to develop and bundle relevant competencies. This refers, for example, to the localization and centralization of relevant knowledge and skills in organizations to initiate and accompany innovation initiatives. Furthermore, practitioners perceive a challenge with respect to the mindset that is needed in the context of digital innovation. This is especially urgent when digital innovation is seen as an on-going effort, and not only a one-off project (Mendling et al., 2020).

\section{Based on our findings, we encourage future research to make contributions to understanding} and demonstrating the facilitating role of organizational capabilities in leveraging digital opportunities to BPM activities and, vice versa. (Research direction 3).

The established BPM literature has addressed the role of organizational alignment. One suggestion, for example, is to implement BPM units, such as centers of excellence, which would be responsible for translating an organization's strategy into BPM initiatives (Štemberger, Buh, Glavan, \& Mendling, 2018). Furthermore, the role of mindset has been considered in the research on BPM culture, which associates cultural values with successful BPM activities (Schmiedel, vom Brocke, \& Recker, 2015). As innovation has not been a core part of BPM (Recker, 2014), these approaches do not fully capitalize on the role of digital innovation. For example, BPM units are seen as translators between higher-level organizational strategies and lower-level operations. BPM itself is not strongly involved in higher-level strategic decisionmaking, e.g. in guiding innovation activities. Similarly, the values of a BPM culture cover the commitment within an organization to innovate; however, this commitment refers to innovation that takes place within business process or of business processes (e.g. by making them more efficient or effective) (Schmiedel, Recker, \& vom Brocke, 2020). To fully capture the mindset sketched out before, it would also be important to assess the commitment to design innovations through or in terms of business processes (Wurm et al., 2019).

Table 1 summarizes the main outcomes of this report. It depicts the three research directions as well as the opportunities and challenges associated with them. Furthermore, it points to existing concepts and ideas to exemplify how these research directions can be promoted. 


\begin{tabular}{|c|c|c|c|}
\hline $\begin{array}{l}\text { Research } \\
\text { direction }\end{array}$ & $\begin{array}{l}\text { BPM challenges in light of } \\
\text { digital innovation }\end{array}$ & Associated opportunities & $\begin{array}{l}\text { Relevant } \\
\text { concepts (exem- } \\
\text { plary) }\end{array}$ \\
\hline \multirow{2}{*}{$\begin{array}{l}\text { Exploring } \\
\text { the role of } \\
\text { BPM in digi- } \\
\text { tal innova- } \\
\quad \text { tion }\end{array}$} & $\begin{array}{l}\text { Limited awareness of the } \\
\text { enabling role of BPM in } \\
\text { digital innovation initia- } \\
\text { tives (Mendling et al., } \\
\text { 2020) }\end{array}$ & $\begin{array}{l}\text { Exploring how BPM can play an } \\
\text { enabling role in digital innova- } \\
\text { tion (in descriptive and prescrip- } \\
\text { tive terms) (Van Looy, 2021) }\end{array}$ & $\begin{array}{l}\text { Collection of in- } \\
\text { novative BPM } \\
\text { cases (vom } \\
\text { Brocke \& } \\
\text { Mendling, 2018) }\end{array}$ \\
\hline & $\begin{array}{l}\text { The BPM discourse is } \\
\text { largely concerned with ex- } \\
\text { ploitative BPM (Benner \& } \\
\text { Tushman, 2003; Groß et } \\
\text { al., 2019; Rosemann, } \\
\text { 2014) }\end{array}$ & $\begin{array}{l}\text { Advancing explorative BPM ac- } \\
\text { tivities, i.e., attempts to integrate } \\
\text { emerging innovation opportuni- } \\
\text { ties into business process work } \\
\text { (Grisold et al., 2019; Groß et al., } \\
\text { in press; Kohlborn et al., 2014; } \\
\text { Rosemann, 2014) }\end{array}$ & $\begin{array}{l}\text { Explorative BPM } \\
\text { (Helbin \& Van } \\
\text { Looy, 2021; } \\
\text { Rosemann, 2014) }\end{array}$ \\
\hline \multirow{2}{*}{$\begin{array}{l}\text { Scoping digi- } \\
\text { tal innova- } \\
\text { tion activities } \\
\text { within BPM } \\
\text { initiatives }\end{array}$} & $\begin{array}{l}\text { Practitioners are unaware } \\
\text { of how they should inte- } \\
\text { grate digital innovation ac- } \\
\text { tivities within their BPM } \\
\text { projects }\end{array}$ & $\begin{array}{l}\text { Further understanding and } \\
\text { demonstrating how digital inno- } \\
\text { vation can support BPM activi- } \\
\text { ties }\end{array}$ & $\begin{array}{l}\text { Business Process } \\
\text { Design Space } \\
\text { (Groß et al., in } \\
\text { press) }\end{array}$ \\
\hline & $\begin{array}{l}\text { Little concrete guidance on } \\
\text { how to manage BPM pro- } \\
\text { jects in the context of digi- } \\
\text { tal innovation }\end{array}$ & $\begin{array}{l}\text { Conducting descriptive and ex- } \\
\text { planatory research designs to in- } \\
\text { form the design of appropriate } \\
\text { BPM frameworks, methods, and } \\
\text { tools (Badakhshan, Conboy, } \\
\text { Grisold, \& vom Brocke, 2019) }\end{array}$ & $\begin{array}{l}\text { BPM Billboard } \\
\text { (vom Brocke, } \\
\text { Mendling, et al., } \\
\text { 2021) }\end{array}$ \\
\hline \multirow{2}{*}{$\begin{array}{l}\text { Aligning or- } \\
\text { ganizational } \\
\text { structures to } \\
\text { realize digi- } \\
\text { tal innova- } \\
\text { tions } \\
\text { through } \\
\text { BPM }\end{array}$} & $\begin{array}{l}\text { Little guidance on how to } \\
\text { develop and bundle rele- } \\
\text { vant competencies }\end{array}$ & $\begin{array}{l}\text { Defining and describing capabil- } \\
\text { ities to enable BPM for digital } \\
\text { innovation }\end{array}$ & 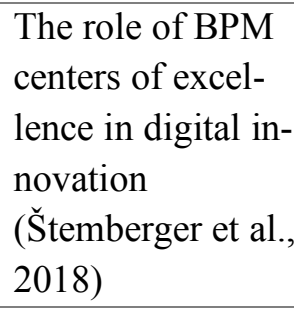 \\
\hline & $\begin{array}{l}\text { Unclear role of mindset } \\
\text { needed in the context of } \\
\text { digital innovation }\end{array}$ & $\begin{array}{l}\text { Promoting innovation mindset } \\
\text { and logics within the BPM do- } \\
\text { main (Baiyere et al., 2020) }\end{array}$ & $\begin{array}{l}\text { BPM culture in } \\
\text { the context of dig- } \\
\text { tal innovation } \\
\text { (Schmiedel et al., } \\
\text { 2020) }\end{array}$ \\
\hline
\end{tabular}

Table 1: Summary of the research directives as well as associated challenges, opportunities and relevant concepts

We see several avenues to advance the connection between digital innovation and BPM. First, it is important to implement an organizational culture that fosters the continuous and openended exploration of innovation opportunities (Grisold et al., 2019; Mendling et al., 2020). Furthermore, business processes should not only be considered as a means to an end (i.e. to operationalize innovation) but to be at the core of digital innovation. Important questions are, for example, how this awareness can be built up and how this form of culture can be developed and maintained. Recent findings stress that BPM culture develops through the implementation 
and use of BPM tools (Schmiedel et al., 2020). In this vein, it would be interesting to see if and to what extent innovation management methods (such as design thinking) can influence the culture in relation to digital innovation in the context of BPM. Another point that seems relevant is the integration of digital innovation competencies in relation to BPM. This poses several questions, relating, for example, to the role of BPM units in the broader context of the organization, or who should be part of such teams in addition to BPM experts. A final point that seems worthwhile to pursue is the question of how digital innovation activities can be measured by means of process KPIs. Established KPIs tend to focus on quality, price, and efficiency (Dumas et al., 2018). In the context of unfolding innovation activities where organizations experiment with new ideas (Mendling et al., 2020), it seems relevant to introduce KPIs that measure the progress of such activities .

\section{Conclusion}

In this report, we summarized the findings we gained through a large-scale online workshop series with practitioners. Focusing on the connection and interplay between digital innovation and BPM, we developed a thorough understanding of practitioners' perceived opportunities and challenges. In addition, we collected data through two surveys which provided additional insights. We discussed these findings in relation to the existing BPM literature and identified three directives for future research. First, we found that it is important to explore the role that BPM plays in digital innovation. Second, we require empirical evidence on how digital innovation can be enhanced within BPM projects. Third, we need to develop a theoretical perspective on the role of organizational structures that best enable digital innovation and BPM.

\section{Acknowledgements:}

This report has been funded by the ERASMUS+ program of the European Union (EU Funding 2018-1-LI01-KA203-000114 "Reference Module Design for Explorative Business Process Management"). We would like to express our gratitude to the European Union and AIBA Liechtenstein for their support.

\section{References}

Badakhshan, P., Conboy, K., Grisold, T., \& vom Brocke, J. (2019). Agile business process management: A systematic literature review and an integrated framework. Business Process Management Journal, 26(6), 1505-1523.

Baiyere, A., Salmela, H., \& Tapanainen, T. (2020). Digital transformation and the new logics of business process management. European journal of information systems, 29(3), 238259.

Benner, M. J., \& Tushman, M. L. (2003). Exploitation, exploration, and process management: The productivity dilemma revisited. Academy of Management Review, 28(2), 238-256.

Berente, N., \& Lee, J. (2014). How process improvement efforts can drive organisational innovativeness. Technology Analysis \& Strategic Management, 26(4), 417-433. 
Berger, S., Denner, M.-S., \& Roeglinger, M. (2018). The nature of digital technologiesdevelopment of a multi-layer taxonomy. Paper presented at the 26th European Conference on Information Systems, Portsmouth, UK.

Beverungen, D., Buijs, J. C., Becker, J., Di Ciccio, C., van der Aalst, W. M., Bartelheimer, C., ... Leopold, H. (2020). Seven Paradoxes of Business Process Management in a HyperConnected World. Business \& Information Systems Engineering, 1-12.

Denner, M.-S., Püschel, L. C., \& Röglinger, M. (2018). How to exploit the digitalization potential of business processes. Business \& Information Systems Engineering, 60(4), 331-349.

Dumas, M., La Rosa, M., Mendling, J., \& Reijers, H. A. (2018). Fundamentals of business process management (Second Edition ed.): Springer.

Gartner. (2019). Market Guide for Process Mining. Retrieved from https://www.gartner.com/en/documents/3939836/market-guide-for-process-mining

Grisold, T., Gross, S., Röglinger, M., Stelzl, K., \& vom Brocke, j. (2019). Exploring Explorative BPM - Setting the Ground for Future Research. In T. Hildebrandt, B. F. van Dongen, M. Röglinger, \& J. Mendling (Eds.), Business Process Management. BPM 2019. (Vol. 11675). Cham: Springer.

Grisold, T., Mendling, J., Otto, M., \& vom Brocke, J. (2020). Adoption, use and management of process mining in practice. Business Process Management Journal, 27(2), 369-387.

Groß, S., Malinova, M., \& Mendling, J. (2019). Navigating Through the Maze of Business Process Change Methods. Paper presented at the Proceedings of the 52nd Hawaii International Conference on System Sciences.

Groß, S., Stelzl, K., Grisold, T., Mendling, J., Röglinger, M., \& vom Brocke, J. (in press). The Business Process Design Space for Exploring Process Redesign Alternatives. . Business Process Management Journal.

Helbin, T., \& Van Looy, A. (2021). Is Business Process Management (BPM) Ready for Ambidexterity? Conceptualization, Implementation Guidelines and Research Agenda. Sustainability, 13(4), 1906.

Kerpedzhiev, G. D., König, U. M., Röglinger, M., \& Rosemann, M. (2020). An exploration into future business process management capabilities in view of digitalization. Business \& Information Systems Engineering, 1-14.

Kohlborn, T., Mueller, O., Poeppelbuss, J., \& Roeglinger, M. (2014). Interview with Michael Rosemann on ambidextrous business process management. Business Process Management Journal, 20(4), 634-638.

Kreuzer, T., Röglinger, M., \& Rupprecht, L. (2020). Customer-centric prioritization of process improvement projects. Decision Support Systems, 133, 113286.

Lehnert, M., Linhart, A., \& Röglinger, M. (2016). Value-based process project portfolio management: integrated planning of BPM capability development and process improvement. Business Research, 9(2), 377-419.

Mendling, J., Pentland, B. T., \& Recker, J. (2020). Building a Complementary Agenda for Business Process Management and Digital Innovation. European journal of information systems, 29(3), 208-219. 
Mikalef, P., \& Krogstie, J. (2020). Examining the interplay between big data analytics and contextual factors in driving process innovation capabilities. European journal of information systems, 29(3), 260-287.

Recker, J. (2014). Suggestions for the next wave of BPM research: strengthening the theoretical core and exploring the protective belt. Journal of Information Technology Theory and Application, 15(2), 5-20.

Rosemann, M. (2014). Proposals for future BPM research directions. Paper presented the Asia-Pacific conference on business process management.

Schmiedel, T., Recker, J., \& vom Brocke, J. (2020). The relation between BPM culture, BPM methods, and process performance: Evidence from quantitative field studies. Information \& Management, 57(2), 103175.

Schmiedel, T., vom Brocke, J., \& Recker, J. (2015). Culture in business process management: how cultural values determine BPM success. In Handbook on Business Process Management 2 (pp. 649-663): Springer.

Seidel, S., \& Watson, R. (2020). Integrating Explanatory/Predictive and Prescriptive Science in Information Systems Research. Communications of the Association for Information Systems, 47, $284-314$.

Simmert, B., Ebel, P. A., Peters, C., Bittner, E. A. C., \& Leimeister, J. M. (2019). Conquering the challenge of continuous business model improvement. Business \& Information Systems Engineering, 61(4), 451-468.

Štemberger, M. I., Buh, B., Glavan, L. M., \& Mendling, J. (2018). Propositions on the interaction of organizational culture with other factors in the context of BPM adoption. Business Process Management Journal, 24(2), 425-445.

Van Looy, A. (2021). A quantitative and qualitative study of the link between business process management and digital innovation. Information \& Management, 58(2), 103413.

vom Brocke, J., Denner, M.-S., Schmiedel, T., Stelzl, K., Röglinger, M., \& Wehking, C. (2021). Context-Aware Business Process Management Method Assessment and Selection. Business \& Information Systems Engineering.

vom Brocke, J., \& Grisold, T. (2020). Erfolgreich Digitalisieren - Ansätze für ein modernes Prozessmanagement. Controlling, 20, 102-107.

vom Brocke, J., Grisold, T., Gross, S., Mendling, J., Röglinger, M., \& Stelzl, K. (2020). Class Notes: Teaching the Five-Diamond Method for Explorative BPM. Retrieved from https://www.bptrends.com/class-notes-teaching-the-five-diamond-method-forexplorative-bpm/

vom Brocke, J., \& Mendling, J. (2018). Business process management cases. Heidelberg: Springer.

vom Brocke, J., Mendling, J., \& Rosemann, M. (2021). Planning and Scoping Business Process Management with the BPM Billboard. In J. vom Brocke, J. Mendling, \& M. Rosemann (Eds.), Business Process Management Cases (Vol. 2). Heidelberg: Springer.

Wurm, B., Goel, K., Bandara, W., \& Rosemann, M. (2019). Design Patterns for Business Process Individualization. Paper presented at the International Conference on Business Process Management. 
Yoo, Y., Henfridsson, O., \& Lyytinen, K. (2010). Research commentary-the new organizing logic of digital innovation: an agenda for information systems research. Information Systems Research, 21(4), 724-735. 